Wirhiams, P. P. \& Doetsch, R. N. (1960). J. gen. Microbiol. 22, 635-644

\title{
Microbial Dissimilation of Galactomannan
}

\author{
By P. P. WILliams and R. N. DOETSCH \\ Departments of Microbiology and Dairy Science, University of Maryland, College \\ Park, Maryland, U.S.A.
}

SUMMARY: A number of obligately anaerobic rumen streptococci have been found capable of hydrolysing a mannan, galactomannan, contained in the endosperm of Cyamopsis tetragonaloba. Some of their morphological, cultural and physiological characteristics have been determined. The enzyme(s) associated with the breakdown of galactomannan is termed 'galactomannanase'. It is possessed by some authentic rumen bacteria, and it is also found in significant amounts in raw rumen liquor. Galactomannanase in bacteria-free rumen fluid is postulated to be released into it by the prior growth of micro-organisms attacking the $\beta-1: 4$ linkage such as cellulose, cellulose derivatives and galactomannan. A survey of a number of non-rumen bacteria revealed that they do not elaborate galactomannanase. Ability to hydrolyse galactomannan seems confined to a specialized group of anaerobic cocci of the rumen. Procedures for the purification of galactomannan and galactomannanase are described.

During the course of investigation on 'bloat', a serious malady of ruminants characterized by inability to expel ruminal metabolic gases, experiments were conducted on the supposition that increased viscosity of the rumen liquor would result in the formation of a stable foam, and that this would tend to block the cardia, interfering with eructation (Boda, Silver, Colvin \& Cole, 1957). An attempt was made to increase artificially the viscosity of rumen liquor by the addition of guar gum. This substance has the property of producing a strong gel in low concentration due to its galactomannan content (Fig. 1).

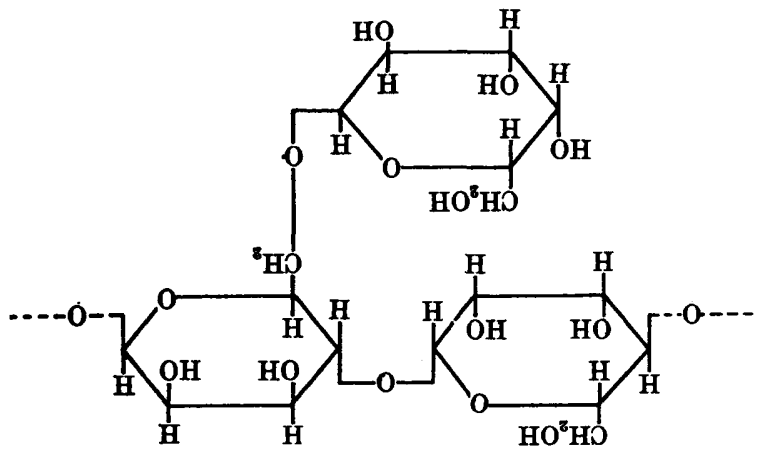

Fig. 1. Structural formula of galactomannan.

It was found, contrary to expectations, that there was, in fact, no increase in viscosity of the rumen contents. The question arose concerning the role of rumen bacteria in degrading galactomannan; and the purpose of this investigation, then, was to attempt to isolate and characterize organisms capable of 
utilizing a mannan, guar gum, as a sole carbohydrate source. In addition, some of the properties of the enzyme were determined, and an explanation is offered for the presence of this enzyme in rumen liquor.

\section{METHODS}

\section{General culture methods}

Rumen samples were obtained from a permanently fistulated Holstein cow, maintained on an alfalfa hay-grain mixture diet, as described by Gibbons, Doetsch \& Shaw (1955). Samples were weighed directly into milk dilution bottles for use as inocula. The dilution fluid contained per litre: $\mathrm{Na}_{2} \mathrm{HPO}_{4}$, $5 \cdot 2$ g., $\mathrm{KH}_{2} \mathrm{PO}_{4}, 4.6$ g.; $\mathrm{Na}_{2} \mathrm{CO}_{3}, 5.0$ g.; sodium thioglycollate, 1.0 g.; and resazurin, $1.0 \mathrm{mg}$.; under an atmosphere of oxygen-free carbon dioxide.

The anaerobic techniques used were essentially those described by Hungate (1950), and modified by Doetsch, Robinson \& Shaw (1952), and Bryant \& Burkey (1953). All cultures were incubated at $37^{\circ}$ under an atmosphere of oxygen-free carbon dioxide, unless otherwise indicated.

The principal medium used in this investigation for isolation and maintenance of cultures was galactomannan-trypticase medium (GTM). The galactomannan was purified from commercially available guar gum and incorporated into this medium in a concentration of $0.4 \%(w / v)$. The medium contained the following ingredients (sterilized by autoclaving at $121^{\circ}$ for $20 \mathrm{~min}$.) per $100 \mathrm{ml}$.; $15 \mathrm{ml}$. of a salts solution consisting of: $(\%, w / v), \mathrm{KH}_{2} \mathrm{PO}_{4}, 0.3$; $\left(\mathrm{NH}_{4}\right)_{2} \mathrm{SO}_{4}, 0.6 ; \mathrm{MgSO}_{4}, 0.02 ; \mathrm{CaCl}_{2}, 0.02$, and $15 \mathrm{ml}$. of a solution of $\mathrm{K}_{2} \mathrm{HPO}_{4}$, 0.3; resazurin, $0.1 \mathrm{mg}$.; sodium thioglycollate, 0.08 g.; trypticase (B.B.L.), $1.0 \mathrm{~g}$; ; and agar, if a solid medium was desired, $2 \cdot 0 \mathrm{~g}$. After sterilization, $10 \mathrm{ml}$. Seitz-filtered sodium carbonate $(3 \%, \mathrm{w} / \mathrm{v})$ were added to give a final concentration of $0 \cdot 3 \%(w / v)$.

\section{Purification of galactomannan}

The purest grade of guar gum commercially available contains much fibrous material and other extraneous substances which render it unsuitable for use in GTM medium and viscosimetric studies. Therefore, a purification procedure was employed. The guar gum in $0.5 \%(\mathrm{w} / \mathrm{v})$ aqueous suspension was heated to $100^{\circ}$ for $4 \mathrm{hr}$., after which the fibrous material was removed by filtering the solution through glass wool. After cooling, $15 \mathrm{ml}$. of toluene and $2.0 \mathrm{~g}$. of trypsin were added to 5.0 l. of the filtrate in $6 \mathrm{l}$. Erlenmeyer flasks. The toluene was added to prevent microbial destruction of the galactomannan, and the trypsin removed intimately bound protein. The solution was incubated for $16 \mathrm{hr}$. at $37^{\circ}$. The galactomannan was then precipitated from the aqueous solution with an equal volume of $95 \%(\mathrm{v} / \mathrm{v})$ ethanol, and redissolved in a minimum amount of water. Five per cent $(w / v)$ trichloroacetic acid was added to precipitate protein, and the solution was centrifuged at $550 \mathrm{~g}$ for 15 min. to sediment the precipitated material. The supernatant was gently agitated and an equal volume of $95 \%(\mathrm{v} / \mathrm{v})$ ethanol was added to precipitate the galactomannan. The precipitated carbohydrate was then redissolved in a minimum amount of water. 
The process of precipitating and redissolving the galactomannan was repeated three successive times to rid the polysaccharide of traces of trichloroacetic acid. In the last precipitation, the galactomannan was removed from the aqueous-ethanol solution by filtering through a Buchner funnel and Whatman no. 1 filter paper. The galactomannan was dried in vacuo in a desiccator over concentrated sulphuric acid and calcium chloride. Analysis of the purified galactomannan, a white granular powder, showed a reduction to $0.014 \%$ nitrogen from the $5.36 \%$ nitrogen originally in the guar gum. Ash content was reduced from 0.8 to $0.05 \%$. When total carbohydrate was measured using anthrone reagent (Morris, 1948), a reading of 257 Klett units (KlettSummerson photoelectric colorimeter Model 800-3) measured at $655 \mathrm{~m} \mu$, was obtained from $200 \mu \mathrm{g} / \mathrm{ml}$. of purified galactomannan. A 2:1 mixture of $200 \mu \mathrm{g}$ / ml. of D-mannose and D-galactose yielded a value of 262 Klett units. The galactomannan obtained in this manner still retained gelling properties in aqueous solution, but strong gels were not formed in as low a concentration as with commercial guar gum.

\section{Pure culture studies}

Eighteen pure cultures of rumen bacteria able to hydrolyse both $\mathbf{0 . 0 2 5} \%$ $(w / v)$ aqueous galactomannan solution, as determined viscosimetrically, and $2.0 \%(w / v)$ aqueous guar gum gels, were isolated, and biochemical determinations were made using the substrates shown in Table 1 . The initial $\mathbf{p H}$ was adjusted to 6.9 in all media which were of the same composition as GTM, with the addition of $10 \%(\mathrm{v} / \mathrm{v})$ rumen fluid (centrifuged at $250 \mathrm{~g}$ for $15 \mathrm{~min}$.) whilst $1 \%(w / v)$ test substrate was substituted for galactomannan.

A survey of a number of bacteria of non-ruminal origin was made to determine the distribution of 'galactomannanase' activity. These micro-organisms were grown in nutrient broth supplemented with galactomannan (0.5\%, w/v) as well as in GTM medium under the cultural conditions required for the rumen bacteria. The non-rumen bacteria tested were: Bacillus cereus var. mycoides, B. cereus, Streptococcus faecalis, S. pyogenes, Pseudomonas aeruginosa, Micrococcus citreus, M. caseolyticus, Proteus vulgaris, P. mirabilis, Escherichia coli, Sarcina lutea, Aerobacter aerogenes and Gafflya tetragena. The cultures, after $48 \mathrm{hr}$. incubation at $37^{\circ}$, were centrifuged at $13,000 \mathrm{~g}$ for $15 \mathrm{~min}$. Two ml. of each supernatant were added to $18 \mathrm{ml}$. of $1 \%(\mathrm{w} / \mathrm{v})$ galactomannan in phosphate buffer at $\mathbf{p H ~ 6 . 9 . ~ I n a c t i v a t i o n ~ o f ~ e n z y m e s ~ i n ~ t h e ~ s u p e r n a t a n t ~ w a s ~}$ accomplished by exposure to boiling water for $10 \mathrm{~min}$. and cooling. Comparisons of inactivated with activated solutions were made viscosimetrically.

Thirty cultures of rumen bacteria, isolated by Gilroy (1957) on $4 \%(v / v)$ rumen fluid glucose-cellobiose medium (RFGC), were also screened for galactomannanase activity. These cultures were inoculated into GTM and RFGC plus $1 \%(w / v)$ galactomannan media, and tested in the manner outlined above.

Purification of galactomannanase

A galactomannan-hydrolysing culture, no. 10, was incubated under anaerobic conditions in 5 l. GTM medium in 6 l. Erlenmeyer flasks for 7 days, 
and a modification of the procedure for enzyme purification was carried out on the supernatant as described by O'Brien \& Campbell (1957) using precipitation and elution methods. The Ostwald viscometer, which has been thoroughly described and evaluated for studies of this sort by Levinson \& Reese (1950), was employed to determine the kinetics of galactomannan degradation, as well as the pH and temperature optima for galactomannanase.

\section{Chemical and viscometric studies}

Culture no. 10 was inoculated into GTM medium containing $1 \%(w / v)$ galactomannan to determine loss of total carbohydrate after $48 \mathrm{hr}$. at $37^{\circ}$ by the anthrone method (Morris, 1948). Fermentation acids were qualitatively and quantitatively determined, using a modification of the column chromatographic technique described by Wiseman \& Irvin (1957). Colorimetric determination of reducing sugars, resulting from the hydrolysis of galactomannan, was carried out using the method of Folin \& Malmros (1929). Paper chromatography for detection of reducing sugars was employed (Partridge, 1948) using the solvent system, butanol-acetic acid-water $4: 1: 5(\mathrm{v} / \mathrm{v} / \mathrm{v})$ and aniline hydrogen phthalate as the colouring reagent.

Determination of galactomannanase activity in the presence of other carbohydrates was accomplished by inoculating the rumen isolates into a medium consisting of GTM medium, without galactomannan, but containing $1 \%(w / v)$ of either lactose, sucrose, soluble starch, cellulose gum (Hercules Powder Co. type 70-high, no. 1307, Wilmington, Delaware, U.S.A.), a wood cellulose, 'Solka-Floc' (Brown Co., Berlin, New Hampshire, U.S.A.), saponin or mannose. Number 2 leafy alfalfa hay, in concentrations of 2 and $5 \%(w / v)$, was also used as a substrate. The inoculated media were incubated at $37^{\circ}$ for $72 \mathrm{hr}$, with the exception of the cellulose medium, which was incubated for 14 days. Supernatants of each medium, obtained by centrifuging at $13,000 \mathrm{~g}$ for 15 min., were incorporated into galactomannan solution, and comparisons were made between inactivated and unheated supernatant-galactomannan solutions by the viscometric methods outlined in the section on 'Pure culture studies'.

Determination of optimum $\mathrm{pH}$ for enzymic activity was accomplished viscometrically at $37^{\circ}$, by diluting the purified enzyme solution with $\mathrm{M} / 15$ phosphate buffer at $\mathrm{pH} 7.0$ and dispensing in $0.025 \%(\mathrm{w} / \mathrm{v})$ galactomannan solution. Samples of this latter solution were previously adjusted to a $\mathrm{pH}$ ranging from 4.0 to 10.0 at 0.5 unit increments using $0.1 \mathrm{~m}$-citrate buffer for pH 4.0; $\mathrm{M} / 15$ phosphate buffer for $\mathrm{pH} \mathrm{4.5-8.5;}$ and $0.2 \mathrm{M}$-glycine-NaOH

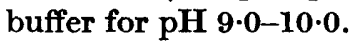

The effect of temperature on enzyme activity was determined viscometrically at $\mathrm{pH} \mathrm{7.0}$ over a temperature range of $20-70^{\circ}$ at $10^{\circ}$ increments using $0.025 \%(w / v)$ galactomannan as substrate. Effect of a heavy metal on enzyme activity was noted viscometrically using copper ions $\left(\mathrm{Cu}^{++}\right)$in the form of copper sulphate at molar concentrations of $10^{-2}$ to $10^{-6}$. These solutions were buffered with $\mathrm{M} / 15$ phosphate at $\mathrm{pH} 7 \cdot 0$. 
Absorbancy readings were made at $520 \mathrm{~m} \mu$ for detection of reducing sugars after the enzyme-substrate mixture had reacted for $50 \mathrm{~min}$. at $37^{\circ}$, using the Folin-Malmros technique (1929).

\section{RESULTS}

\section{Characterization of the organisms}

Galactomannan hydrolysing rumen bacteria are Gram-positive non-motile streptococci. They are rapidly growing obligate anaerobes (especially in the GTM medium devoid of agar) which form on GTM solid medium 2-4 mm. non-pigmented colonies possessing a light blue fluorescent colouration when viewed by transmitted light. Morphologically, the streptococci range in size from 0.3 to $0.6 \mu$ in diameter, and occur singly or form chains of 3-4 cells. Rumen samples cultured for 'galactomannanase'-positive bacteria yielded numbers as high as $4 \times 10^{8} / \mathrm{g}$. wet weight.

The fermentative abilities of 6 of 18 cultures are shown in Table 1. The remaining 12 cultures showed similar fermentation patterns. The isolates rapidly hydrolysed starch, raffinose, cellobiose, trehalose, and salicin. No activity was noted on cellulose, gum ghatti, and gum arabic.

Non-rumen bacteria grown in the presence of galactomannan, both aerobically and, where possible, anaerobically, did not possess galactomannanase activity. Among the rumen bacteria isolated by Gilroy (1957) from a medium not containing galactomannan (RFGC), only 4 of 30 cultures tested were galactomannanase-positive. The positive organisms were all obligately anaerobic cocci occurring in pairs.

\section{Enzyme-substrate studies}

The purification procedure for galactomannanase from 5 l. of GTM medium, in which culture no. 10 had grown for 7 days at $37^{\circ}$, resulted in a preparation having 100 units of enzyme per ml. as compared to the culture supernatant, which contained only 3 units of enzyme per ml. One unit of enzyme was arbitrarily defined as that amount of enzyme capable of hydrolysing buffered $0.025 \%(w / v)$ galactomannan solution at $\mathrm{pH} 7 \cdot 0$ and $37^{\circ}$ to half viscosity within 6 min.

There was a $33 \%$ loss of carbohydrate in the GTM medium inoculated with culture no. 10 after $48 \mathrm{hr}$. incubation at $37^{\circ}$. Fermentation products (acids) from $100 \mu \mathrm{M}$ galactomannan were found to be $178 \mu \mathrm{M}$ of lactic, $34 \mu \mathrm{m}$ of formic and 18.4 $\mu \mathrm{m}$ of acetic. Reducing sugars were liberated by the action of purified galactomannanase on galactomannan. The reaction of the concentrated enzyme solution on a purified galactomannan solution is illustrated in Fig. 2.

Monosaccharides, galactose and mannose, were not detected by the chromatographic technique employed. Although oligosaccharides cannot be detected by the method employed, the absence of monosaccharides from the enzyme-substrate mixture suggests that the reducing sugars produced as determined by the Folin-Malmros technique are perhaps oligosaccharides such as mannobiose (Whistler \& Stein, 1951), or mannotriose (Whistler \& Smith, 1952). 
Table 1. Fermentation of various substrates by galactomannan-hydrolysing bacteria

The concentration of substrate in the medium was $1 \%(w / v)$. The substrates were sterilized separately by Seitz filtration of a concentrated aqueous solution except in the case of polysaccharides (cellulose, starch, gum arabic, gum ghatti) which were sterilized by autoclaving at $121^{\circ}$ for 10 min. Determination of final pH was made electrometrically after 6 days (1st column) and 12 days (2nd column) at $37^{\circ}$. Controls (inoculated media minus substrate, and uninoculated media with substrate) gave final readings of $6 \cdot 7-6 \cdot 9$.

Final pH of culture number

\begin{tabular}{|c|c|c|c|c|c|c|c|c|c|c|c|c|}
\hline \multirow{5}{*}{\begin{tabular}{l}
\multicolumn{1}{c}{ Substrate } \\
Aldohexoses \\
D-(+)-Glucose \\
D-(+)-Galactose \\
D-(+)-Mannose
\end{tabular}} & \multicolumn{2}{|c|}{1} & \multicolumn{2}{|c|}{2} & \multicolumn{2}{|c|}{10} & \multicolumn{2}{|c|}{15} & \multicolumn{2}{|c|}{17} & \multicolumn{2}{|c|}{18} \\
\hline & & & & & & & & & & & & \\
\hline & $4 \cdot 2$ & $4 \cdot 4$ & $4 \cdot 4$ & $4 \cdot 4$ & $4 \cdot 5$ & 4.5 & $4 \cdot 35$ & 4.55 & $4 \cdot 3$ & 4.5 & $5 \cdot 5$ & $5 \cdot 5$ \\
\hline & $4 \cdot 5$ & $4 \cdot 5$ & $4 \cdot 3$ & $4 \cdot 3$ & $4 \cdot 65$ & 4.5 & $4 \cdot 65$ & $4 \cdot 6$ & $4 \cdot 5$ & $4 \cdot 5$ & $5 \cdot 6$ & $5 \cdot 6$ \\
\hline & $5 \cdot 0$ & $4 \cdot 9$ & $4 \cdot 9$ & $4 \cdot 8$ & 4.5 & $4 \cdot 3$ & $4 \cdot 6$ & $4 \cdot 6$ & $5 \cdot 0$ & $4 \cdot 8$ & $5 \cdot 4$ & $5 \cdot 45$ \\
\hline Sugar alcohols & & & & & & & & & & & & \\
\hline Dulcitol & $6 \cdot 0$ & $6 \cdot 2$ & $6 \cdot 2$ & $6 \cdot 2$ & $6 \cdot 0$ & 6.0 & $6 \cdot 3$ & $6 \cdot 3$ & 6.5 & 6.5 & $6 \cdot 3$ & $6 \cdot 4$ \\
\hline Sorbitol & $5 \cdot 8$ & $6 \cdot 2$ & $5 \cdot 8$ & $\mathbf{5 \cdot 9}$ & $6 \cdot 1$ & $5 \cdot 85$ & $6 \cdot 1$ & $6 \cdot 3$ & $6 \cdot 1$ & $6 \cdot 0$ & $5 \cdot 4$ & $5 \cdot 4$ \\
\hline Mannitol & $4 \cdot 65$ & 4.7 & $5 \cdot 9$ & $6 \cdot 0$ & $6 \cdot 1$ & $6 \cdot 1$ & $6 \cdot 25$ & $6 \cdot 3$ & $4 \cdot 6$ & $4 \cdot 4$ & $5 \cdot 2$ & $5 \cdot 4$ \\
\hline Disaccharides & & & & & & & & & & & & \\
\hline Cellobiose & $4 \cdot 3$ & $4 \cdot 4$ & $4 \cdot 35$ & $4 \cdot 4$ & 4.5 & $4 \cdot 4$ & $4 \cdot 6$ & $4 \cdot 6$ & $4 \cdot 3$ & $4 \cdot 4$ & $5 \cdot 4$ & $5 \cdot 4$ \\
\hline Trehalose & $4 \cdot 4$ & $4 \cdot 6$ & $6 \cdot 5$ & $6 \cdot 6$ & 4.7 & $4 \cdot 75$ & $4 \cdot 75$ & $4 \cdot 75$ & $5 \cdot 4$ & $5 \cdot 4$ & $5 \cdot 5$ & $5 \cdot 7$ \\
\hline Trisaccharide & & & & & & & & & & & & \\
\hline Raffinose & $4 \cdot 4$ & $4 \cdot 5$ & $4 \cdot 3$ & $4 \cdot 4$ & $4 \cdot 55$ & $4 \cdot 55$ & 4.75 & 4.70 & $4 \cdot 4$ & $4 \cdot 5$ & $5 \cdot 8$ & $5 \cdot 7$ \\
\hline Glucoside & & & & & & & & & & & & \\
\hline Salicin & 4.95 & $5 \cdot 0$ & $5 \cdot 0$ & $4 \cdot 9$ & $5 \cdot 15$ & $5 \cdot 05$ & $\mathbf{5 \cdot 3}$ & $\mathbf{5 \cdot 3 5}$ & $6 \cdot 6$ & $6 \cdot 5$ & $\mathbf{5} \cdot \boldsymbol{9}$ & $5 \cdot 9$ \\
\hline Polysaccharides & & & & & & & & & & & & \\
\hline Gum arabic & 6.25 & $6 \cdot 3$ & $6 \cdot 5$ & $6 \cdot 4$ & $6 \cdot 6$ & $6 \cdot 6$ & $6 \cdot 75$ & 6.7 & $6 \cdot 6$ & $6 \cdot 7$ & $6 \cdot 5$ & $6 \cdot 45$ \\
\hline Gum ghatti & $6 \cdot 5$ & $6 \cdot 5$ & $6 \cdot 6$ & $6 \cdot 6$ & $6 \cdot 7$ & $6 \cdot 6$ & $6 \cdot 35$ & $6 \cdot 4$ & $6 \cdot 6$ & $6 \cdot 7$ & $6 \cdot 5$ & $6 \cdot 6$ \\
\hline
\end{tabular}

Cellulose

In all cases, starch was hydrolysed and cellulose was not attacked. 
Supernatants from lactose, sucrose, saponin, mannose, and soluble starch media in which organism no. 10 had grown did not hydrolyse guar gum or galactomannan; however, the supernatants from media containing cellulose gum, 'Solka-Floc', and alfalfa readily hydrolysed galactomannan.

The optimum temperature for galactomannanase under the conditions previously described was $35^{\circ}$, and the optimum $\mathrm{pH}$ was found to be $\mathbf{7 \cdot 0}$. Enzyme activity was inhibited at concentrations of copper ions from $10^{-4}$ to $10^{-2} \mathrm{M}$.

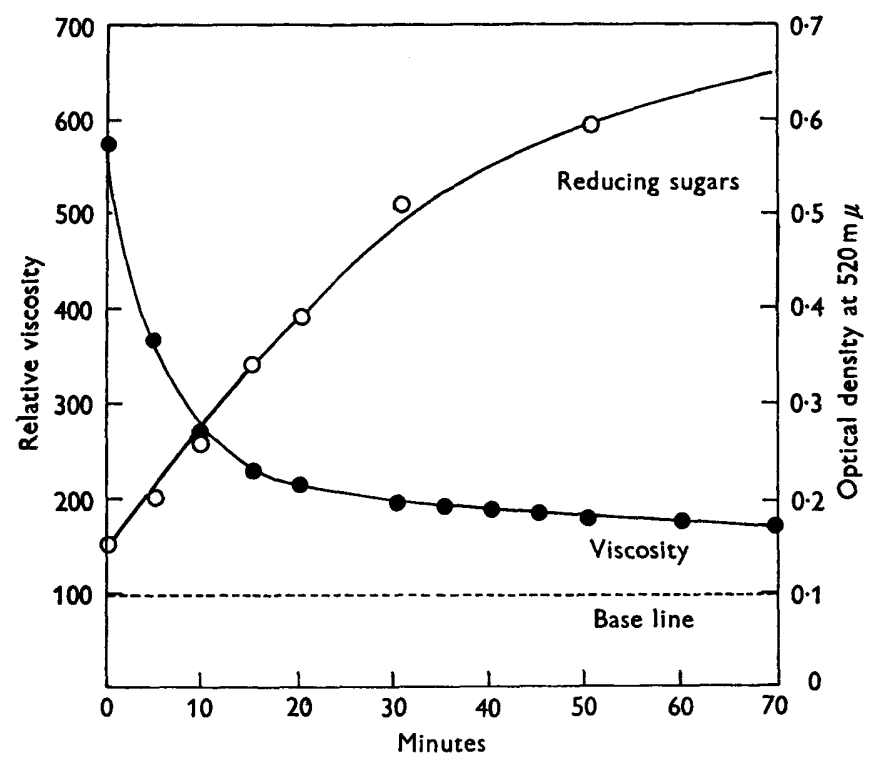

Fig. 2. Liberation of reducing sugars, as measured by the Folin-Malmros technique, and decrease in viscosity of galactomannan by a purified enzyme preparation, from a galactomannan hydrolysing coccus no. 10. Reaction mixture contained $9.9 \mathrm{ml}$. $0.025 \%(w / v)$ purified galactomannan in $\mathrm{m} / 15$ phosphate buffer at $\mathrm{pH} 7 \cdot 0$, and $0 \cdot 1 \mathrm{ml}$. of a $1: 2$ dilution of purified enzyme preparation in the same buffer. Temperature, $37^{\circ}$. Relative viscosity $=\frac{\text { flow time of reaction solution }}{\text { flow time of water }} \times 100$.

\section{DISCUSSION}

Mannans are polysaccharides composed essentially of mannose units and are widespread in nature. They occur either in simple form, or as one of the socalled 'paired mannans' (glucomannan, galactomannan, fructomannan), and are found in nearly all plants. Pigman (1957) noted that soft woods contain $11 \%$ D-mannose; and Whistler \& Smart (1953) discovered a rich source of mannan in the taqua palm, as well as the tubers of orchids, and the red alga, Porphyra umbilicalis. These higher plant mannans are structurally distinct from the highly branched mannans of yeast, known as 'yeast gum', which along with glycogen are the polysaccharide constituents of Saccharomyces cerevisiae (Chung \& Nickerson, 1954). Mannans are also present in seeds of fodder plants as lespediza, birds-foot trefoil (Lotus corniculatus), sweet clover 
(Melilotus) and alfalfa (lucerne, Medicago), (Hirst, Jones \& Walden, 1947). The galactomannan of guar gum, found in the endosperm of Cyamopsis tetragonaloba, is a complex polymer of galactose and mannose. It is an essentially straight chain mannan and has a molecular weight of 220,000. The mannose units, of which there are approximately 270 per chain, are linked in a $\beta$-1:4-glycosidic configuration and galactose branching takes place by means of a $\beta-1: 6$ linkage and occurs on alternate mannose units (Fig. 1). Knowledge of the microbial enzymic degradation of mannans (even though the substrates are widespread in nature) is quite limited (Manners, 1955).

Explanations for the presence of galactomannan-degrading enzymes in rumen fluid may be offered: (1) microbial capsular polysaccharides, slime and other materials serve as substrate(s), or perhaps (2) plant fragments and rumen protozoa contain enzyme(s) capable of degrading galactomannan. Although the latter possibility has not been ruled out, the results here indicate that galactomannan-degrading bacteria are present in appreciable numbers in the rumen. The concept that 'cellulase' is a single enzyme must be viewed with reserve. Gill \& King (1957) have noted that there are at least three protein species in the soluble portion of rumen ingesta which, when separated electrophoretically, catalyse the hydrolysis of carboxymethyl cellulose gum. It may be that galactomannanase is a 'type' of cellulase, since both cellulase and galactomannanase are glycosidases and attack $\beta-1: 4$ linkages. It should be kept in mind, however, as pointed out by Halliwell (1957), that the action of pure isolates or of mixed rumen bacteria on any form of cellulose does not a priori signify that other substrates are likewise susceptible to attack.

There is a similarity between the activities of a commercially prepared cellulase (Bios Laboratories, New York) and galactomannanase in that both are capable of liberating ortho-nitrophenyl from ortho-nitrophenyl $\beta$-D galactopyranoside, and, further, in that the cellulase also hydrolysed galactomannan.

The enzyme(s) responsible for the degradation of pentosans, xylans, cellulose derivatives, and mannans seems to be the same 'type' of enzyme, that is, one or several enzymes capable of splitting complex $\beta-1: 4$ glycosidic linkages without resulting in much hexose or pentose products, but rather an accumulation of intermediate oligosaccharides suitable for further rumen microbial dissimilation. Howard (1957) has observed the production of xylose, xylobiose, xylotriose, xylotetraose, and xylopentaose by the action of rumen bacteria suspensions on purified pentosans. In this case, the polysaccharide consisted of a main chain of $D$-xylopyranose units, linked $\beta-1: 4$ with single $L$-arabofuranoside units attached along the chain at positions 2 and 3 of the xylose.

The rumen isolates grown on GTM medium containing galactomannan as the sole carbon source seem, taxonomically, most closely allied to the genus Ruminococcus, both morphologically and physiologically (Bryant, Small, Bouma \& Robinson, 1958). The rumen isolates differ from described species, however, in their inability to hydrolyse cellulose. The organisms studied in this work also exhibit some affinities with bacteria of the genus Peptostreptococcus (Bergey's Manual, 1957), but certainly cannot be considered to be any 
of the presently described species. Other organisms demonstrated capable of hydrolysing mannans include the mould Neurospora sitophila, the marine alga Cladophora rupestris, and an agar-hydrolysing bacterium isolated by Ishimatsu \& Kibesaki (1952).

Mannan hydrolysis has also been studied by Bierry \& Giaja (1912) using as substrate material from date palm and ivory nut plants, with enzyme preparations from the gastric juices of the crayfish, crab, lobster, and the snail, Helix pomatia. Pringsheim \& Genin (1924) noted that salep mannan was hydrolysed by an aqueous extract of barley malt.

The ability to hydrolyse natural mannans is obviously not an exclusive characteristic of bacteria. Nevertheless, among bacteria, this property is not widely distributed, but rather, at least at the present state of our knowledge, seems to reside in a specialized group of anaerobic cocci of the rumen. Doubtless, knowledge concerning this group of organisms may be of aid in shedding light on the physiological features of rumen fermentations. In addition, the ready availability, relative ease of preparation, and the stability of galactomannanase make it an interesting subject for continued study of bacterial hydrolytic enzyme systems.

This work was supported in part by Animal Disease and Parasite Division, A.R.S., U.S.D.A. The authors wish to thank the Stein Hall Co., New York, N.Y., for a generous gift of guar gum ('Jaguar' brand) and to Dr Sitarama Lakshmanan for his helpful suggestions for a procedure for the purification of galactomannan.

Scientific article no. A-794. contribution no. 3062, of the Maryland Agriculture Experiment Station.

\section{REFERENCES}

Bergey's Manual of Determinative Bacteriology (1957). 7th ed. Ed. R. S. Breed, E. G. D. Murray \& N. R. Smith. Baltimore: The Williams and Wilkins Co.

Bierry, H. \& GiaJA, J. (1912). Enzymes which attack mannans, galactans, and celluloses. Biochem. J. 40, 370.

Boda, J. M., Sirver, B. S., Colvin, Jun., W. H. \& Cole, H. H. (1957). Studies on the experimental production and prevention of bloat in cattle. I. Influence of intrarumen administration of fresh eggwhite on the production of bloat. J. Dairy Sci. 40, 759.

Bryant, M. P. \& Burkey, L. A. (1953). Numbers of some predominant groups of bacteria in the rumen of cows fed different rations. J. Dairy Sci. 36, 218.

Bryant, M. P., Small, N., Bouma, C. \& Robinson, I. M. (1958). Characteristics of ruminal anaerobic cellulolytic cocci and Cillobacterium cellulosolvens n.sp. J. Bact. 76, 529.

Chung, C. W. \& Nickerson, W. J. (1954). Polysaccharide synthesis in growing yeasts. J. biol. Chem. 208, 395.

Doetsch, R. N., Robinson, R. Q. \& Shaw, J. C. (1952). Techniques employed in cultural investigations of the bacteriology of bovine rumen contents. $J$. Anim. Sci. 11, 536.

Folrn, O. \& Malmros, H. (1929). An improved form of Folin's micro method for blood sugar determination. J. biol. Chem. 83, 115 .

Grbeons, R. J., Doetsch, R. N. \& Shaw, J. C. (1955). Further studies on polysaccharide production by bovine rumen bacteria. J. Dairy Sci. 38, 1147 .

GiLL, J. W. \& KING, K. W. (1957). Characteristics of free rumen cellulases. Agric. dE Food Chem. 5, 363. 
GILroy, J. J. (1957). Nitrogen requirements for growth of bovine rumen bacteria. Ph.D. thesis, University of Maryland.

Halliwell, G. (1957). Cellulolysis by rumen microorganisms. J. gen. Microbiol. 17, 153.

Hirst, E. L., Jones, J. K. N. \& Waiden, W. O. (1947). The galactomannan of the lucerne seed. J. chem. Soc. p. 1443.

HowARD, B. H. (1957). Hydrolysis of the soluble pentosans of wheat flour and Rhodymenia palmata by ruminal microorganisms. Biochem. J. 67, 643 .

Hungate, R. E. (1950). The anaerobic mesophilic cellulolytic bacteria. Bact. Rev. $14,1$.

Ishimatsu, K. \& KrbesAKI, Y. (1952). Mannanase of the agar-agar splitting bacteria. Chem. Abstr. 46, 2124d. (Original in Symposia on Enzyme Chemistry (Japan), 4, 75 (1950).)

Levinson, H. S. \& ReEsE, E. T. (1950). Enzymatic hydrolysis of soluble cellulase derivative as measured by changes in viscosity. J. gen. Physiol, 33, 601 .

Manners, D. J. (1955). Enzyme degradation of polysaccharides. Quart. Revs. Chem. Soc. Lond. 9, 73.

Morris, D. L. (1948). Quantitative determination of carbohydrate with Dreywood's anthrone reagent. Science, 107, 254.

O'Brien, R. T. \& Camprell, L. L., Jr. (1957). Purification and properties of a proteolytic enzyme from Bacillus stearothermophilus. Arch. Biochem. Biophys. 70, 432.

Partridge, S. M. (1948). Filter-paper partition chromatography of sugars. Biochem. J. 42, 238.

Pigman, W. (1957). The Carbohydrates. New York: Academic Press.

Pringshem, H. \& Genin, A. (1924). Über die fermentative Spaltung des Salepmannans. Hoppe-Seyl. Z. 140, 299.

Whistler, R. L. \& Smart, C. L. (1953). Polysaccharide Chemistry. New York: Academic Press.

Whistler, R. L. \& Smith, C. G. (1952). A crystalline mannotriose from the enzymatic hydrolysis of guaran. J. Amer. chem. Soc. 74, 3795.

Whistler, R. L. \& Stein, J. (1951). A crystalline mannobiose from the enzymatic hydrolysis of guaran. J. Amer. chem. Soc. 73, 4187.

Wiseman, H. G. \& Irvin, H. M. (1957). Determination of organic acids in silage. Agric. \& Food Chem. 5, 213. 